\title{
Retention and caries-preventive effect of glass ionomer and resin-based sealants: An 18-month-randomized clinical trial
}

\author{
Asma AL-JOBAIR ${ }^{1}$, Nouf AL-HAMMAD ${ }^{1}$, Salwa ALSADHAN² and Fouad SALAMA ${ }^{1}$ \\ ${ }^{1}$ Department of Pediatric Dentistry and Orthodontics, College of Dentistry, King Saud University, Riyadh, Saudi Arabia \\ ${ }^{2}$ Department of Periodontics and Community Dentistry, College of Dentistry, King Saud University, Riyadh, Saudi Arabia \\ Corresponding author, Asma AL-JOBAIR; E-mail: aaljobair@ksu.edu.sa
}

\begin{abstract}
The objective of this study was to compare the retention and caries-preventive effect of glass ionomer (Fuji Triage) and resin-based (Clinpro) sealants among 6-9-year-old children. This split-mouth, randomized clinical trial covered 35 children/140 fully erupted permanent first molars. Evaluation was conducted by two independent examiners after 6, 12, and 18 months and the data were compared in relation to the children's caries risk and age groups. The Kaplan-Meier survival method and chi-square test were used for analysis. There were no statistically significant differences in the survival of partial and fully retained sealants or in the survival of caries-free pits and fissures between glass-ionomer and resin-based sealants. In terms of retention, both sealants performed better in the younger age group at the end of the study, and showed better caries prevention in moderate caries risk children. After 18 months, both sealants had comparable retention and caries-preventive effects in 6-9-year old children.
\end{abstract}

Keywords: Sealant retention, Caries prevention, Glass ionomer sealants, Resin-based sealant

\section{INTRODUCTION}

Dental caries is one of the most common conditions affecting the general health of children ${ }^{1)}$. Its prevalence in developed countries is declining, while in underdeveloped and developing countries, the prevalence of caries is rising ${ }^{11}$. In the United Kingdom, from 1973 to 2013, the caries prevalence decreased from $72 \%$ to $41 \%$ in 5 -year-olds, and from $97 \%$ to $46 \%$ in 15 -year-olds ${ }^{2)}$. In the United Sates, from 2002 to 2012, caries declined among children and adolescents from $54.1 \%$ to $45.2 \%^{3}$. In contrast, the prevalence of dental caries in the primary dentition of children under 6 years of age in Saudi Arabia has reached $84 \%$, and by the age of 9 years, the prevalence has reached $94 \%{ }^{4}$. Dental caries was found to be the most common reason for extraction of teeth among Saudis aged 10-30 years, with the first permanent molars being the most frequently extracted teeth ${ }^{5}$. It is estimated that the cost to treat all children aged 14 years or younger in Saudi Arabia would be around 3.9 billion Saudi Riyals (more than US $\$ 1$ billion), assuming a prevalence of approximately $84 \%$ and approximately six decayed teeth per child ${ }^{6}$. Therefore, tremendous monetary benefits could be expected if primary prevention of dental caries, especially among children, is implemented. Thus, dental caries in Saudi Arabia is a significant public health problem among children and adolescents that demands a public health solution.

Although dental caries is an infective transmittable bacterial disease characterized by multi-factorial pathology, it is a disease that can be prevented and even potentially reversed during its early stages ${ }^{7}$.

Color figures can be viewed in the online issue, which is available at J-STAGE

Received Jun 20, 2016: Accepted Jan 19, 2017

doi:10.4012/dmj.2016-225 JOI JST.JSTAGE/dmj/2016-225
Preventive measures such as plaque control and topical fluoride application may not be effective, particularly on susceptible tooth surfaces ${ }^{8}$. More effective measures are therefore necessary, such as the application of occlusal sealants ${ }^{9}$. The use of fissure sealants has been well documented in several clinical studies as an effective measure for the prevention of pit and fissure caries in children. It is highly recommended for populations with high caries prevalence such as Saudi children and adolescents ${ }^{9,10)}$. It is also recommended for high risk surfaces such as occlusal surfaces. Pit and fissure caries accounts for approximately $90 \%$ of the total incidence of caries in children and adolescents, affecting mainly first permanent molars ${ }^{11,12)}$. In 2012 , the prevalence of dental sealants in the US was $36.0 \%^{3)}$, while the prevalence of dental sealants among Saudi schoolchildren was $9.0 \%{ }^{13)}$. The application of fissure sealants through school-based dental programs is urgently needed to prevent dental caries among Saudi schoolchildren.

Resin-based sealants are effective in preventing caries; however, they are moisture sensitive ${ }^{14)}$. In contrast, glass ionomer cement has the advantage of being moisture tolerant and offering continuous fluoride release; however, its effect on caries prevention is questionable because of its inadequate retention rate ${ }^{15,16)}$. Although numerous clinical studies have provided conflicting evidence regarding the retention and cariespreventive effect of glass ionomer sealants ${ }^{16-18)}$, metaanalysis conducted to compare the caries-preventive effect of glass ionomer cement with resin-based fissure sealants found no evidence that either material was superior to the other in the prevention of dental caries $^{19,20)}$. Therefore, the aim of this randomized clinical trial was to compare the retention and caries-preventive effect of glass ionomer and resin-based sealants among 
6-9-year-old children. The null hypothesis tested was that there is no difference in the retention and cariespreventive effect of glass ionomer and resin-based sealants in 6-9-year-old children.

\section{MATERIALS AND METHODS}

\section{Study population}

Ethical clearance to conduct the study was obtained from the Human Ethical Committee at the College of Dentistry Research Center (CDRC) at King Saud University (NF2260).

Eighty-five children attending dental clinics at the College of Dentistry, King Saud University (KSU), were screened and examined by a single experienced examiner using a mouth mirror and dental explorer. The inclusion criteria for the selected children were: healthy cooperative children aged 6-9 years; all four permanent first molars fully erupted; with deep pits and fissures; free of caries, restorations, or sealant; and with $\mathrm{dmft} \geq 1$. Out of the 85 children examined, 42 fulfilled the inclusion criteria, and 35 were retained through the whole study period. On the first visit to the pediatric dental clinic, the subject's medical and dental history was reviewed. After the research was explained, a written consent to participate in the study was signed by the child's parent. Each child's teeth were examined, and all present, carious, filled and missing teeth were recorded in standard dental charts according to the diagnostic criteria of the World Health Organization Oral Health Survey ${ }^{21}$. Individual caries risk was based on the baseline dmft index of each patient. Standardized bitewing radiographs for all the children were taken on the first visit to finalize the treatment plan. If any evidence of radiolucency was seen on the occlusal or proximal surfaces of the first permanent molars, the children were excluded from the study. Other reasons for exclusion included stained grooves, suspected carious lesions and enamel hypoplasia.

\section{Sealant application}

A table of random numbers determined the material to be used on the right side of the mouth. A single operator carried out all clinical procedures starting with prophylaxis using a slurry of pumice and a rotating brush. The occlusal surfaces of all four first permanent molars were then thoroughly flushed with water. The permanent first molars were isolated using cotton rolls (Distech ${ }^{\circledR}$ Cotton Rolls, Montreal, Canada) and a saliva ejector held by a dental assistant. Sealants were applied using a split-mouth technique. Two permanent first molars on one side of the mouth were sealed with Clinpro (Clinpro ${ }^{\mathrm{TM}}$ Sealant, 3M ESPE, St. Paul, MN, USA), a light-cure low viscosity fluoride-releasing resin-based sealant. The contralateral two permanent first molars were sealed with Fuji Triage (GC Fuji Triage, GC, Tokyo, Japan), a chemical-cured low viscosity high-fluoride releasing glass ionomer sealant. The chemical composition of the tested materials is presented in Table 1. Clinpro was applied following the manufacturer's instructions. The occlusal surface was dried and 35\% phosphoric acid was applied with a disposable brush into the pits and fissures. Each tooth was etched for $30 \mathrm{~s}$ and then rinsed thoroughly for $10 \mathrm{~s}$ using an oil-free air-water syringe. Etching was confirmed by a dull frosty-white appearance of the enamel. The sealant was then applied and cured for 30 s using a light cure unit (Elipar ${ }^{\mathrm{TM}}$ S10, 3M ESPE). Each sealant was checked using a dental explorer which was run over the sealed surface to ensure that there was a smooth marginal seal between the sealant and the tooth surface and that the sealant covered all pits and fissures and resisted removal. The occlusion was checked with articulating paper (Coltene Whaledent, Cuyahoga Falls, $\mathrm{OH}$, USA) to confirm that there were no premature contacts that might cause occlusal interference. The white-colored Fuji Triage was also applied according to the manufacturer's instructions on the contralateral teeth. The occlusal surfaces were conditioned with GC cavity conditioner for $10 \mathrm{~s}$, rinsed for $10 \mathrm{~s}$, and then dried by blotting with a cotton pellet. The sealant was triturated and directly applied to the occlusal surface. A disposable soft brush was used to spread it into the pits and fissures. Then, the sealant margins were checked using a dental explorer, and the occlusion was checked as for the resin-based sealants. All other dental treatment was performed according to individual treatment plans for all children involved in the study. All children and their parents were directed to follow similar preventive program that included oral hygiene instructions, use of fluoridated toothpaste, and diet counseling.

Table 1 Chemical composition of tested materials

\begin{tabular}{|c|c|c|}
\hline Sealant & Material & Composition \\
\hline $\begin{array}{l}\text { Glass Ionomer } \\
\text { Sealant }\end{array}$ & $\begin{array}{l}\text { GC Fuji } \\
\text { Triage }\end{array}$ & $\begin{array}{l}\text { aluminofluorosilicate glass, polyacrylic acid, distilled water, } \\
\text { pigment, polybase carboxylic acid }\end{array}$ \\
\hline $\begin{array}{l}\text { Resin-based } \\
\text { Sealant }\end{array}$ & $\begin{array}{l}\text { Clinpro }^{\mathrm{TM}} \\
\text { Sealant }\end{array}$ & $\begin{array}{l}\text { triethyleneglycol dimethacrylate (TEGDMA), bisphenol A diglycidyl ether } \\
\text { dimethacrylate (Bis-GMA), silane treated silica, tetrabutylammonium } \\
\text { tetrafluoroborate, diphenyliodonium hexafluorophosphate, triphenylantimony, } \\
\text { ethyl 4-dimethyl aminobenzoate (EDMAB), titanium dioxide, hydroquinone }\end{array}$ \\
\hline
\end{tabular}




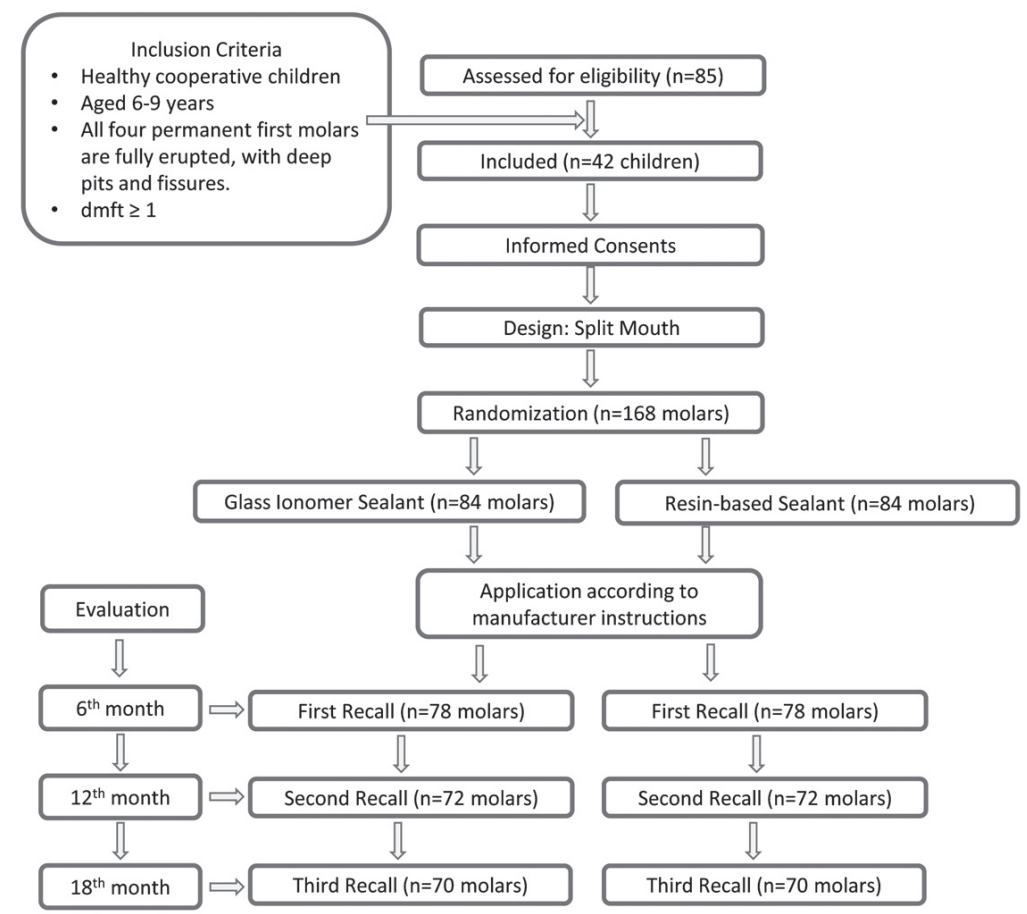

Fig. 1 Flow diagram of the current study. $\mathrm{n}=$ number

\section{Evaluation}

All the participating children were recalled for evaluation of sealant retention and the presence or absence of caries after 6,12 , and 18 months by two calibrated and experienced independent evaluators. The evaluators were blinded because both sealant materials were similar in appearance. At each evaluation, and for each evaluator, a new record form was used to prevent examiner bias from knowledge of the previous evaluation. All fissure sealants were examined with a dental explorer to verify the retention of the sealant. Sealant retention was categorized into three groups according to the method of Oulis and Berdouses ${ }^{22)}$ : "Total Retention"=total retention of the sealant on the occlusal surface, "Partial Loss"=presence of the sealant with fracture or loss of material, and "Total Loss"=total absence of the sealant on the occlusal surface. Carious lesions were assessed using a dental explorer according to the diagnostic criteria of the World Health Organization Oral Health Survey ${ }^{21)}$ after drying the occlusal surfaces with air. After evaluation at each recall visit, topical fluoride gel (acidulated phosphate fluoride, $1.23 \%$ ) was applied to each participating child.

For the sake of comparison, the study children were divided into two groups according to age and caries risk. The two age groups were $6-7$ and $8-9$ years. The two categories of caries risk severity, according to the method of Oulis and Berdouses ${ }^{22}$, were moderate risk (MR; dmft score of 1-4) and high risk (HR; dmft score of $>4)$.

\section{Statistical analysis}

The data were analyzed using SPSS statistical package software, version 20 (IBM, Armonk, NY, USA). KaplanMeier survival analysis was performed to compare the survival rate in retention and caries prevention of both sealants. The long-rank test was used to test the significance of survival curves between the materials. The chi-square test was used to compare the two sealants in relation to age group and caries risk. The $p$ value was set at 0.05 . To confirm intra- and inter-examiner reproducibility for the clinical evaluation concerning sealant retention and caries presence, a kappa test was performed. Figure 1 shows a flowchart of the study design and the number of participants and teeth at each evaluation period of the study.

\section{RESULTS}

The results of the two examinations on sealant status showed good intra-examiner reproducibility, with kappa values of 0.87 for sealant retention and 0.90 for the presence of caries. The kappa test also showed good inter-examiner reproducibility with a value of 0.84 .

One-hundred and forty teeth in 35 children with an average age of 7.2 years (range 6-9 years) were included and evaluated. Seven children were lost over the 1.5year follow-up period due to loss of contact and were not included in the statistical analysis.

Table 2 and Figs. 2 and 3 show the comparative cumulative survival percentage of partially and fully retained sealants, and the cumulative survival 
Table 2 Cumulative survival percentages, means and standard errors of partially and fully retained sealants and cariesfree pits and fissures of first permanent molars over a period of 18 months

\begin{tabular}{|c|c|c|c|c|c|c|}
\hline Outcome & $\begin{array}{l}\text { Sealant } \\
\text { material }\end{array}$ & $\begin{array}{c}\text { Cumulative survival } \\
\%\end{array}$ & Mean & $\begin{array}{l}\text { Standard } \\
\text { Error }\end{array}$ & $\begin{array}{c}\text { Confidence Interval } \\
95 \%\end{array}$ & $p$ \\
\hline \multirow{2}{*}{ Retention } & Fuji Triage & 89.6 & 17.2 & 0.187 & $(16.9-17.6)$ & \multirow{2}{*}{0.171} \\
\hline & Clinpro & 92.9 & 17.6 & 0.119 & (17.4-17.9) & \\
\hline \multirow{2}{*}{ Caries Prevention } & Fuji Triage & 85.7 & 17.2 & 0.190 & $(16.8-17.5)$ & \multirow{2}{*}{0.235} \\
\hline & Clinpro & 88.9 & 17.4 & 0.162 & $(17.1-17.7)$ & \\
\hline
\end{tabular}

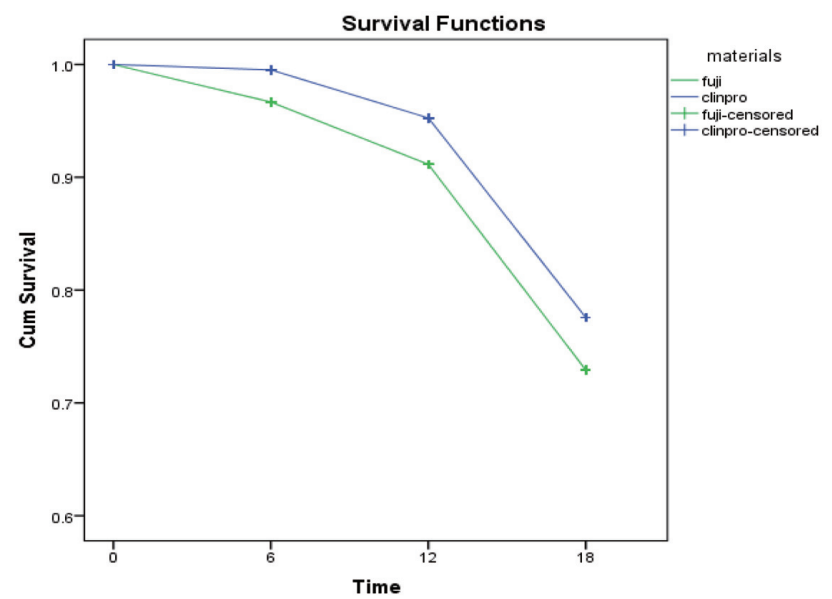

Fig. 2 Comparison of the cumulative survival percentages of partially and fully retained glass ionomer and resin-based sealants over a period of 18 months.

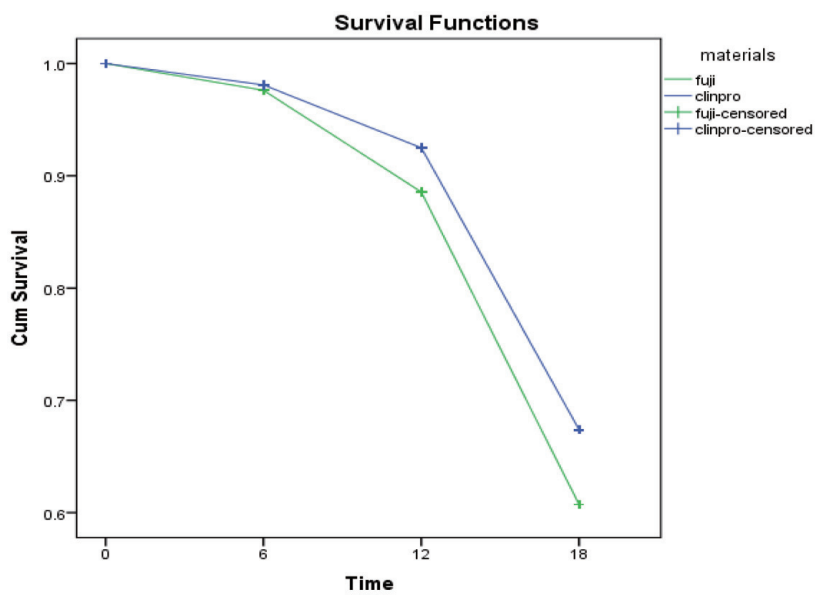

Fig. 3 Comparison of the cumulative survival percentages of caries-free pits and fissures of glass ionomer and resin-based sealants over a period of 18 months.

Table 3 Comparison of the retention of glass ionomer (Fuji Triage) and resin-based (Clinpro) sealants in different caries risk and age groups

\begin{tabular}{|c|c|c|c|c|c|c|c|c|c|c|c|}
\hline \multirow{4}{*}{$\begin{array}{l}\text { Evaluation } \\
\text { Period }\end{array}$} & \multirow{4}{*}{ Retention } & \multirow{3}{*}{$\begin{array}{c}\text { Fuji } \\
\text { Triage }\end{array}$} & \multirow{3}{*}{$\begin{array}{l}\text { Clinpro } \\
(n=70)\end{array}$} & \multicolumn{2}{|c|}{ Fuji Triage } & \multicolumn{2}{|c|}{ Clinpro } & \multicolumn{2}{|c|}{ Fuji Triage } & \multicolumn{2}{|c|}{ Clinpro } \\
\hline & & & & \multicolumn{4}{|c|}{ Caries Risk } & \multicolumn{4}{|c|}{ Age Groups } \\
\hline & & & & $\begin{array}{c}\mathrm{MR} \\
(n=40)\end{array}$ & $\begin{array}{c}\mathrm{HR} \\
(n=30)\end{array}$ & $\begin{array}{c}\text { MR } \\
(n=40)\end{array}$ & $\begin{array}{c}\mathrm{HR} \\
(n=30)\end{array}$ & $\begin{array}{c}6-7 \\
(n=34)\end{array}$ & $\begin{array}{c}8-9 \\
(n=36)\end{array}$ & $\begin{array}{c}6-7 \\
(n=34)\end{array}$ & $\begin{array}{c}8-9 \\
(n=36)\end{array}$ \\
\hline & & No. $(\%)$ & No. $(\%)$ & No. $(\%)$ & No. (\%) & No. (\%) & No. $(\%)$ & No. (\%) & No. $(\%)$ & No. (\%) & No. $(\%)$ \\
\hline \multirow{3}{*}{$6^{\text {th }}$ month } & TR & $48(68.6)$ & 47 (67.1) & $26(65)$ & $22(73.3)$ & $28(70)$ & 19 (63.3) & $24(70.6)$ & 24 (66.7) & $20(58.8)$ & $27(75)$ \\
\hline & $\mathrm{PL}$ & $15(21.4)$ & $22(31.4)$ & $8(20)$ & 7 (23.3) & $11(27.5)$ & $11(36.7)$ & $10(29.4)$ & $5(13.9)$ & $13(38.2)$ & $9(25)$ \\
\hline & $\mathrm{TL}$ & $7(10)$ & $1(1.4)$ & $6(15)$ & $1(3.3)$ & $1(2.5)$ & $0(0.0)$ & $0(0)$ & $7(19.4)$ & $1(2.9)$ & $0(0.0)$ \\
\hline \multicolumn{2}{|c|}{$p$} & \multicolumn{2}{|c|}{0.054} & \multicolumn{2}{|c|}{0.273} & \multicolumn{2}{|c|}{0.516} & \multicolumn{2}{|c|}{0.013} & \multicolumn{2}{|c|}{0.275} \\
\hline \multirow{3}{*}{$12^{\text {th }}$ month } & TR & $30(42.9)$ & 33 (47.1) & $15(37.5)$ & $15(50)$ & $19(47.5)$ & $14(46.7)$ & $15(44.1)$ & $15(41.7)$ & $12(35.3)$ & $21(58.3)$ \\
\hline & PL & $32(45.7)$ & $31(49.2)$ & $18(45)$ & $14(40)$ & $19(47.5)$ & $12(46.7)$ & $18(52.9)$ & $14(38.9)$ & $20(58.8)$ & $11(30.6)$ \\
\hline & $\mathrm{TL}$ & 8 (11.4) & $6(8.6)$ & $7(17.5)$ & $1(3.3)$ & $2(5)$ & $4(13.3)$ & $1(2.9)$ & $7(19.4)$ & $2(5.9)$ & $4(11.1)$ \\
\hline \multicolumn{2}{|c|}{$P$} & \multicolumn{2}{|c|}{0.801} & \multicolumn{2}{|c|}{0.162} & \multicolumn{2}{|c|}{0.447} & \multicolumn{2}{|c|}{0.08} & \multicolumn{2}{|c|}{0.05} \\
\hline \multirow{3}{*}{$18^{\text {th }}$ month } & TR & $18(25.7)$ & $23(32.9)$ & $9(22.5)$ & $9(30)$ & $15(37.5)$ & $8(26.7)$ & $10(29.4)$ & $13(36.1)$ & $10(29.4)$ & $13(36.1)$ \\
\hline & PL & $38(54.3)$ & $34(48.6)$ & $20(50)$ & $18(60)$ & $18(45)$ & $16(53.3)$ & $21(61.8)$ & $13(36.1)$ & $21(61.8)$ & $13(36.1)$ \\
\hline & $\mathrm{TL}$ & $14(20)$ & $13(18.6)$ & $11(27.5)$ & $3(10)$ & 7 (17.5) & $6(20)$ & $3(8.8)$ & $10(27.8)$ & $3(8.8)$ & $10(27.8)$ \\
\hline \multicolumn{2}{|c|}{$p$} & \multicolumn{2}{|c|}{0.648} & \multicolumn{2}{|c|}{0.191} & \multicolumn{2}{|c|}{0.633} & \multicolumn{2}{|c|}{0.005} & \multicolumn{2}{|c|}{0.005} \\
\hline
\end{tabular}

No.: Number of teeth, TR: Total Retention, PL: Partial Loss, TL: Total Loss, MR: Moderate Caries Risk, HR: High Caries Risk 
Table 4 Comparison of the caries-preventive effect of glass ionomer (Fuji Triage) and resin-based (Clinpro) sealants in different caries risk and age groups

\begin{tabular}{|c|c|c|c|c|c|c|c|c|c|c|c|}
\hline \multirow{4}{*}{$\begin{array}{l}\text { Evaluation } \\
\text { Period }\end{array}$} & \multirow{4}{*}{ Caries } & \multirow{3}{*}{  } & \multirow{3}{*}{$\begin{array}{l}\text { Clinpro } \\
(n=70)\end{array}$} & \multicolumn{2}{|c|}{ Fuji Triage } & \multicolumn{2}{|c|}{ Clinpro } & \multicolumn{2}{|c|}{ Fuji Triage } & \multicolumn{2}{|c|}{ Clinpro } \\
\hline & & & & \multicolumn{4}{|c|}{ Caries Risk } & \multicolumn{4}{|c|}{ Age Groups } \\
\hline & & & & $\begin{array}{c}\mathrm{MR} \\
(n=40)\end{array}$ & $\begin{array}{c}\mathrm{HR} \\
(n=30)\end{array}$ & $\begin{array}{c}\text { MR } \\
(n=40)\end{array}$ & $\begin{array}{c}\mathrm{HR} \\
(n=30)\end{array}$ & $\begin{array}{c}6-7 \\
(n=34)\end{array}$ & $\begin{array}{c}8-9 \\
(n=36)\end{array}$ & $\begin{array}{c}6-7 \\
(n=34)\end{array}$ & $\begin{array}{c}8-9 \\
(n=36)\end{array}$ \\
\hline & & No. (\%) & No. $(\%)$ & No. $(\%)$ & No. (\%) & No. $(\%)$ & No. $(\%)$ & No. (\%) & No. $(\%)$ & No. (\%) & No. (\%) \\
\hline \multirow{2}{*}{$6^{\text {th }}$ month } & No & $65(92.9)$ & $66(94.3)$ & $39(97.5)$ & $26(86.7)$ & $40(100)$ & $26(86.7)$ & $32(94.1)$ & $33(91.7)$ & $32(94.1)$ & $34(94.9)$ \\
\hline & Yes & $5(7.1)$ & $4(5.7)$ & $1(2.5)$ & $4(13.5)$ & $0(0)$ & $4(13.5)$ & $2(5.9)$ & $3(8.3)$ & $2(5.9)$ & $2(5.6)$ \\
\hline \multicolumn{2}{|c|}{$p$} & \multicolumn{2}{|c|}{1.00} & \multicolumn{2}{|c|}{0.08} & \multicolumn{2}{|c|}{0.017} & \multicolumn{2}{|c|}{0.691} & \multicolumn{2}{|c|}{0.953} \\
\hline $12^{\text {th }}$ month & $\begin{array}{l}\text { No } \\
\text { Yes }\end{array}$ & $\begin{array}{l}57(81.4) \\
13(18.6)\end{array}$ & $\begin{array}{r}62(88.6) \\
8(11.4)\end{array}$ & $\begin{array}{c}37(92.5) \\
3(7.5)\end{array}$ & $\begin{array}{l}20(66.7) \\
10(33.3)\end{array}$ & $\begin{array}{c}39(97.5) \\
1(2.5)\end{array}$ & $\begin{array}{r}23(76.7) \\
7(23.3)\end{array}$ & $\begin{array}{r}27(79.4) \\
7(20.6)\end{array}$ & $\begin{array}{r}30(83.3) \\
6(16.7)\end{array}$ & $\begin{array}{r}28(82.4) \\
6(17.6)\end{array}$ & $\begin{array}{c}34(94.4) \\
2(5.7)\end{array}$ \\
\hline \multicolumn{2}{|c|}{$p$} & \multicolumn{2}{|c|}{0.344} & \multicolumn{2}{|c|}{0.006} & \multicolumn{2}{|c|}{0.007} & \multicolumn{2}{|c|}{0.673} & \multicolumn{2}{|c|}{0.112} \\
\hline $18^{\text {th }}$ month & $\begin{array}{l}\text { No } \\
\text { Yes }\end{array}$ & $\begin{array}{l}48(68.6) \\
22(31.4)\end{array}$ & $\begin{array}{l}51(72.9) \\
19(27.1)\end{array}$ & $\begin{array}{r}33(82.5) \\
7(17.5)\end{array}$ & $\begin{array}{l}15(50) \\
15(50)\end{array}$ & $\begin{array}{c}39(97.5) \\
1(2.5)\end{array}$ & $\begin{array}{l}12(40) \\
18(60)\end{array}$ & $\begin{array}{l}22(64.7) \\
12(35.5)\end{array}$ & $\begin{array}{l}26(72.2) \\
10(27.8)\end{array}$ & $\begin{array}{l}23(67.6) \\
11(32.4)\end{array}$ & $\begin{array}{r}28(77.8) \\
8(22.2)\end{array}$ \\
\hline & & \multicolumn{2}{|c|}{0.711} & \multicolumn{2}{|c|}{0.005} & \multicolumn{2}{|c|}{0.000} & \multicolumn{2}{|c|}{0.498} & \multicolumn{2}{|c|}{0.341} \\
\hline
\end{tabular}

No.: Number of teeth, MR: Moderate Caries Risk, HR: High Caries Risk

percentage of caries-free pits and fissures in the first permanent molars over a period of 18 months using Kaplan-Meier survival analysis. The cumulative survival percentage of partially and fully retained Fuji Triage sealants, was $89.6 \%$, with a mean survival time of 17.2 months. For Clinpro sealants, the cumulative survival percentage of sealant retention was $92.9 \%$, with a mean survival time of 17.6 months. The cumulative survival percentage of caries-free pits and fissures for Fuji Triage sealants was $85.7 \%$, with a mean survival time of 17.2 months; whereas for Clinpro sealants, it was $88.9 \%$, with a mean survival time of 17.4 months. The long-rank test showed that there were no significant differences in the retention rate and caries prevention effect between Fuji Triage and Clinpro sealants with regard to their survival pattern.

Retention rates of both sealants in different caries risk and age groups at 6,12 , and 18 months are shown in Table 3. In general, at the 18-month time period, there was no statistically significant difference in retention between Fuji Triage and Clinpro sealants $(p=0.648)$. However, Fuji Triage and Clinpro both performed better in terms of retention in children in the HR group compared with those in the MR group. Both sealants performed significantly better in the younger age group than in the older age group at 18 months $(p=0.005)$.

The caries-preventive effects of both sealants in different caries risk and age groups at 6, 12 and 18 months are shown in Table 4 . There was no statistically significant difference in the caries-preventive effect between Fuji Triage and Clinpro sealants at the end of the study $(p=0.711)$. Caries was confined to the enamel and no cavitation was observed in either group. Both sealants displayed better caries prevention in the MR group than the HR group, with significant differences at 12 months and 18 months $(p<0.05)$. However, Clinpro provided a better caries-preventive effect in the older age group, whereas Fuji Triage exerted the same preventive effect for both age groups.

\section{DISCUSSION}

The null hypothesis tested in the present study was accepted, as no differences in caries-preventive effect and retention were found between glass ionomer and resin-based sealants among 6-9-year-old children over a period of 18 months.

The success of sealants relies mostly on their effect on caries prevention and retention ${ }^{23)}$. Typically, resinbased sealants are the most frequently used sealant material ${ }^{24)}$. The efficacy of this material depends on the micro-retention provided by enamel tags created by acid etching. However, resin-based sealants are sensitive to moisture, and the hydrophilic characteristics of glass ionomers make them suitable as an alternative to resin-based sealants when moisture contamination is unavoidable ${ }^{24)}$. Resin-based sealants are considered as the positive control in this study because their efficiency in preventing fissure caries is well recognized ${ }^{25)}$. The present study used a split-mouth design to allow control of the oral conditions and to reduce variables, as each child was treated with both types of sealants. Moreover, both types of sealants used in this study were fluoridereleasing and -recharging materials ${ }^{26)}$ to balance the caries-preventive effect provided by the fluoride release and recharge. In our study, rubber dam was not used for isolation as four sealants should be placed in the same visit, and using clamps and rubber dam in each quadrant will cause discomfort for young children which may result in loss of cooperation. Cotton roll and saliva 
ejector hold by dental assistant were used in this study for isolation, a method which has been widely used in many published researches. Also, it has been shown that isolation by rubber dam or cotton rolls are equally effective and result in similar retention rates ${ }^{27,28)}$. Topical fluoride was applied to each child after each recall visit as the participating subjects were moderate to high caries risk children. Possibility effect of topical fluoride on the effectiveness of sealants in fissure caries prevention might exist. In addition, both sealant recharge fluoride from the topical fluoride which may increase the caries-preventive effect of both the sealants ${ }^{29,30)}$. However, in the current study, no difference in caries-preventive effect between the two sealants was observed as the topical fluoride application was applied to all children and balanced by the same type and concentration. Although seven subjects were lost to follow-up in this study, attrition bias was not considered to be a major problem because their data were not incorporated in the statistical analysis.

The present study revealed that after 18 months, the cumulative survival percentages of partially and fully retained Fuji Triage and Clinpro sealants were 89.6\% and $92.9 \%$ respectively, with no significant difference between them. These percentages are higher than those of other study which reported that the 24-month retention rate of glass ionomer and resin-based sealants were 50 and $73 \%{ }^{29)}$. Comparable results were reported in another study in which sealants were provided in a school environment, which found that $93.8 \%$ of resinbased sealants were completely lost 3 years after placement ${ }^{31}$. One clinical study and other field studies found that the retention of resin-based sealants was higher than that of glass-ionomer sealants ${ }^{32-34)}$. For both sealants, the higher survival rate of retention noted in our study could be because both sealants were applied under controlled and dry clinical conditions by a single operator. Although the teeth in our study were fully erupted permanent first molars, another investigation reported similar retention rates of resin-based and glass ionomer sealants in partially erupted permanent molars during a 24-month period and recommended that in cases where salivary contamination was expected, glass ionomer sealants may be a superior option ${ }^{35}$. Many laboratory studies have revealed no significant difference between the sealant penetration, microleakage, or adaptation of both materials under dry conditions ${ }^{36-38)}$. However, an in vitro study showed that Fuji Triage has superior fissure penetration and closer adaptation than Clinpro under wet contaminated environments ${ }^{38}$.

In the present study, no significant difference in the cumulative survival of free-pit and fissure caries was found between Fuji Triage and Clinpro sealants. Similarly, a field study found no significant difference in the cumulative survival of pit and fissure caries between glass-ionomer and resin-based sealants after two years ${ }^{30)}$. Another study reported no significant difference in caries incidence between glass-ionomer and resin-based sealants ${ }^{33}$. However, a clinical study showed that glass ionomer sealants were slightly more efficient in preventing caries than resin-based ${ }^{32}$. The outcomes of our clinical trial are in agreement with the conclusions of earlier published systematic reviews and meta-analyses comparing resin-based and glass-ionomer sealants $^{19,20)}$.

In terms of retention, both sealants performed better in the 6-7-year age group. This could be because immature enamel is porous, and this could assist in sealant retention ${ }^{23,39}$. It has been reported that the best time for sealant application is as soon as the tooth erupts $^{40)}$; nevertheless, sealants placed shortly following tooth eruption have a high risk of failure because oral fluids are likely to contaminate the surface. Previous researchers reported that school-based sealant programs for children should target kindergarten and first grade children because the majority of them have erupted first permanent molars ${ }^{41}$. However, school-based sealant programs tend to have inadequate lighting, saliva control, patient compliance and patient follow-up ${ }^{311}$. In the current study, Fuji Triage and Clinpro both performed better in terms of retention in children in the HR group compared with those in the MR group. However, both sealants had better caries preventive effect in MR group. A study of Chinese children comparing caries prevention and retention of resinbased and glass ionomer sealants among high and low risk caries groups reported no significant difference in the occurrence of caries between the two sealants in either group ${ }^{33}$. However, high risk children with resinbased sealants were more likely to have caries than the low risk group, while there was no difference in caries occurrence between the two groups for glass ionomer sealants ${ }^{33}$. A recent systematic review concluded that resin-based sealants decrease the risk of developing caries for up to 48 months compared with molars without sealants ${ }^{42}$. Another systematic review reported that sealants are effective in high risk children ${ }^{25}$. In our investigation, caries in the primary teeth of the participants $(\mathrm{dmft}=1-4$ or $\mathrm{dmft}>4)$ was used to separate patients into the two groups of high or moderate caries risk, and the results showed that the higher the dmft, the higher the risk of caries development. Both sealants in this study exerted a stronger caries-preventive effect in children in the moderate caries risk group. This outcome is in agreement with the findings of earlier investigations where baseline caries experience was associated with caries development ${ }^{22,33,43}$. It has been reported that the great variability in the reduction of caries is related to the prevalence of caries in the individuals and populations $s^{44)}$. Our study was conducted among children from a high risk population which may explain the obtained results.

The caries preventive properties of sealants are related to the way they physically isolate pits and fissures and/or their ability to release fluoride. One of the main advantages of glass ionomer is fluoride release. In the present study, both sealants contained fluoride. It has been reported that two weeks after application, the fluoride released by Fuji Triage was nine times higher than that released by a resin-based fluoride sealant, as 
well as a greater fluoride recharge capability than other sealants ${ }^{45}$. Furthermore, glass ionomer sealants have been shown to increase the concentration of fluoride in the interproximal fluid to a higher level than did a fluoride-containing resin-based sealant, although both sealants provide added defense for the tooth adjacent to the sealed tooth ${ }^{46)}$. In addition, Fuji Triage improved enamel hardness of the fissure enamel and exhibited the lowest microleakage and proportion of unfilled resin compared with other glass ionomer-based fissure sealant materials $^{47,48)}$.

Although caries was marginally lower and retention was slightly higher in resin-based fissure sealants in this controlled study, glass ionomer sealants showed promising results, especially in high caries risk children. However, further assessment of both sealants for an extended time period is required to assess the occurrence of caries, especially in teeth in which sealants have been partially or completely lost.

A small sample size was one of the limitations of this study as it was difficult to find children with four fully erupted sound first permanent molars, because of the high caries prevalence among Saudi children. Additionally, the time period of 18 months could be considered to be relatively short, but this follow-up time period was chosen to diminish the risk of participants dropping out.

\section{CONCLUSION}

Within the limitations of this randomized clinical trial, it was concluded that after 18 months, both fluoridereleasing sealants (Fuji Triage and Clinpro) had comparable retention and caries-preventive effects in 6-9-year-old children with moderate to high caries risk.

\section{ACKNOWLEDGMENTS}

The authors would like to thank the children who participated in the study and their parents. This study was funded by King Saud University. The study was registered at the College of Dentistry Research Center (NF2260), King Saud University.

\section{REFERENCES}

1) Petersen PE, Bourgeois D, Ogawa H, Estupinan-Day S, Ndiaye C. The global burden of oral diseases and risks to oral health. Bull World Health Organ 2005; 83: 661-669.

2) Murray JJ, Vernazza CR, Holmes RD. Forty years of national surveys: An overview of children's dental health from 19732013. Br Dent J 2015; 219: 281-285.

3) Kumar JV, Tavares V, Kandhari P, Moss M, Jolaoso IA. Changes in caries experience, untreated caries, sealant prevalence, and preventive behavior among third-graders in New York state, 2002-2004 and 2009-2012. Public Health Rep 2015; 130: 355-361.

4) Alagili DE. A systematic review of population-based dental caries studies among children in Saudi Arabia. Saudi Dent J 2013; 25: 3-11.

5) Alesia K, Khalil HS. Reasons for and patterns relating to the extraction of permanent teeth in a subset of the Saudi population. Clin Cosmet Investig Dent 2013; 5: 51-56.

6) Marghalani AA, Alsahafi YA, Alshouibi EN. The cost of dental caries in Saudi Arabia. Putting numbers into context. Saudi Med J 2014; 35: 93-94.

7) Harris NO, Garcia-Godoy F. Primary Preventive Dentistry. 6th ed. New Jersey: Pearson Education; 2004.

8) Ripa LW. Occlusal sealants: rationale and review of clinical trials. Int Dent J 1980; 30: 127-139.

9) Welbury R, Raadal M, Lygidakis NA. EAPD guidelines for the use of pit and fissure sealants. Eur J Paediatr Dent 2004; 5: 179-184.

10) Beauchamp J, Caufield PW, Crall JJ, Donly KJ, Feigal R, Gooch B, Ismail A, Kohn W, Siegal M, Simonsen R. Evidencebased clinical recommendations for the use of pit-and-fissure sealants. A report of the American Dental Association Council on Scientific Affairs. Dent Clin North Am 2009; 53: 131-147.

11) Qi XQ, Zhang BX, Zhang L, Rao KQ. Report on the 3rd National Oral Health Epidemiological Survey. Beijing: The People's Medical Publishing House; 2008. p. 60-63.

12) Brown LJ, Selwitz RH. The impact of recent changes in the epidemiology of dental caries on guidelines for the use of dental sealants. J Public Health Dent 1995; 55: 274-291.

13) Al Agili DE, Niazy HA, Pass MA. Prevalence and socioeconomic determinants of dental sealant use among schoolchildren in Saudi Arabia. East Mediterr Health J 2012; 18: 1209-1216.

14) Silverstone LM, Hicks MJ, Featherstone MJ. Oral fluid contamination of etched enamel surfaces: An SEM study. J Am Dent Assoc 1985; 110: 329-332.

15) Borsatto MC, Corona SA, Alves AG, Chimello DT, Catirse $\mathrm{AB}$, Palma-Dibb RG. Influence of salivary contamination on marginal microleakage of pit and fissure sealants. Am J Dent 2004; 17: 365-367.

16) Poulsen S, Beiruti N, Sadat N. A comparison of retention and the effect on caries of fissure sealing with a glass-ionomer and a resin-based sealant. Community Dent Oral Epidemiol 2001; 29: 298-301.

17) Beiruti N, Frencken JE, van't Hof MA, van Palenstein Helderman WH. Caries-preventive effect of resin-based and glass ionomer sealants over time: a systematic review. Community Dent Oral Epidemiol 2006; 34: 403-409.

18) Ninawe N, Ullal NA, Khandelwal V. A 1-year clinical evaluation of fissure sealants on permanent first molars. Contemp Clin Dent 2012; 3: 54-59.

19) Mickenautsch S, Yengopal V. Caries-preventive effect of glass ionomer and resin-based fissure sealants on permanent teeth: an update of systematic review evidence. BMC Res Notes 2011; 4: 22 .

20) Mickenautsch S, Yengopal V. Caries-preventive effect of highviscosity glass ionomer and resin-based fissure sealants on permanent teeth: A systematic review of clinical trials. PLoS One 2016; 11: e0146512.

21) Oral health survey. Basic Methods. 4th ed. Geneva: World Health Organization; 1997. p. 40

22) Oulis CJ, Berdouses ED. Fissure sealant retention and caries development after resealing on first permanent molars of children with low, moderate and high caries risk. Eur Arch Paediatr Dent 2009; 10: 211-217.

23) Waggoner WF, Siegal M. Pit and fissure sealant application: Updating the technique. J Am Dent Assoc 1996; 127: 351361.

24) Simonsen RJ. Pit and fissure sealant: review of the literature. Pediatr Dent 2002; 24: 393-414.

25) Ahovuo-Saloranta A, Forss H, Walsh T, Hiiri A, Nordblad A, Mäkelä M, Worthington HV. Sealants for preventing dental decay in the permanent teeth. Cochrane Database of Syst Rev 2013; 3: CD001830.

26) Salmerón-Valdés EN, Scougall-Vilchis RJ, Alanis-Tavira J, Morales-Luckie RA. Comparative study of fluoride released and recharged from conventional pit and fissure sealants 
versus surface prereacted glass ionomer technology. J Conserv Dent 2016; 19: 41-45.

27) Eidelman E, Fuks AB, Chosack A. The retention of fissure sealants: rubber dam or cotton rolls in a private practice. ASDC J Dent Child 1983; 50: 259-261.

28) Lygidakis NA, Oulis KI, Christodoulidis A. Evaluation of fissure sealants retention following four different isolation and surface preparation techniques: four years clinical trial. J Clin Pediatr Dent 1994; 19: 23-25

29) Liu BY, Xiao Y, Chu CH, Lo EC. Glass ionomer ART sealant and fluoride releasing resin sealant in fissure caries prevention - results from a randomized clinical trial. BMC Oral Health 2014; 14: 54.

30) Liu BY, Lo EC, Chu CH, Lin HC. Randomized trial on fluorides and sealants for fissure caries prevention. J Dent Res 2012; 91: 753-758.

31) Oba AA, Dülgergil T, Sönmez IS, Doğan S. Comparison of caries prevention with glass ionomer and composite resin fissure sealants. J Formos Med Assoc 2009; 108: 844-848.

32) Ulusu T, Odabas ME, Tuzuner T, Baygin O, Sillelioglu H, Deveci C, Gokdogan FG, Altuntas A. The success rates of a glass ionomer cement and a resin-based fissure sealant placed by fifth-year undergraduate dental students. Eur Arch Paediatr Dent 2012; 13: 94-97.

33) Chen X, Liu X. Clinical comparison of Fuji VII and a resin sealant in children at high and low risk of caries. Dent Mater J 2013; 32: 512-518.

34) Chen X, Du MQ, Fan MW, Mulder J, Huysmans MC, Frencken JE. Caries-preventive effect of sealants produced with altered glass-ionomer materials, after 2 years. Dent Mater 2012; 28: 554-560.

35) Antonson SA, Antonson DE, Brener S, Crutchfield J, Larumbe J, Michaud C, Yazici AR, Hardigan PC, Alempour S, Evans D, Ocanto R. Twenty-four month clinical evaluation of fissure sealants on partially erupted permanent first molars: glassionomer versus resin-based sealant. J Am Dent Assoc 2012; 143: 115-122.

36) Topaloglu Ak A, Riza Alpoz A. Effect of saliva contamination on microleakage of three different pit and fissure sealants. Eur J Paediatr Dent 2010; 11: 93-96.

37) Peng Y, Stark PC, Rich A Jr, Loo CY. Marginal microleakage of triage sealant under different moisture contamination. Pediatr Dent 2011; 33: 203-206.
38) Al-Jobair A. Scanning electron microscope analysis of sealant penetration and adaptation in contaminated fissures. J Indian Soc Pedod Prev Dent 2013; 31: 169-174.

39) Reddy VR, Chowdhary N, Mukunda KS, Kiran NK, Kavyarani BS, Pradeep MC. Retention of resin-based filled and unfilled pit and fissure sealants: A comparative clinical study. Contemp Clin Dent 2015; 6(Suppl 1): S18-23.

40) Feigal RJ, Musherure P, Gillespie B, Levy-Polack M, Quelhas I, Hebling J. Improved sealant retention with bonding agents: a clinical study of two-bottle and single-bottle systems. J Dent Res 2000; 79: 1850-1856.

41) Phipps KR, Ricks TL, Blahut P. Permanent first molar eruption and caries patterns in American Indian and Alaska Native children: challenging the concept of targeting second grade for school-based sealant programs. J Public Health Dent 2013; 73: 175-178.

42) Tikhonova S. Sealing pits and fissures of permanent molars in children and adolescents is effective in controlling dental caries. J Am Dent Assoc 2015; 146: 409-411.

43) Makhija SK, Childers NK, Lauten J, Dorantes CE, Chafin T, Dasanayake AP. Evaluation of initial caries score and caries incidence in a public health sealant program: a retrospective study. Pediatr Dent 2006; 28: 420-424.

44) Leskinen K, Ekman A, Oulis C, Forsberg H, Vadiakas G, Larmas M. Comparison of the effectiveness of fissure sealants in Finland, Sweden, and Greece. Acta Odontol Scand 2008; 66: $65-72$.

45) Bayrak S, Tunc ES, Aksoy A, Ertas E, Guvenc D, Ozer S. Fluoride release and recharge from different materials used as fissure sealants. Eur J Dent 2010; 4: 245-250.

46) Cagetti MG, Carta G, Cocco F, Sale S, Congiu G, Mura A, Strohmenger L, Lingström $\mathrm{P}$, Campus $\mathrm{G}$; Italian Experimental Group on Oral Health. Effect of fluoridated sealants on adjacent tooth surfaces: A 30-mo randomized clinical trial. J Dent Res 2014; 93(7 Suppl): 59S-65S.

47) Haznedaroglu E, Sozkes S, Mentes AR. Microhardness evaluation of enamel adjacent to an improved GIC sealant after different enamel pre-treatment procedures. Eur J Paediatr Dent 2014; 15: 397-400.

48) Kucukyilmaz E, Savas S. Evaluation of shear bond strength, penetration ability, microleakage and remineralisation capacity of glass ionomer-based fissure sealants. Eur J Paediatr Dent 2016; 17: 17-23. 